\title{
AN INVESTIGATION RELATING TO THE APPLICATION OF CAPITAL ASSET PRICING MODEL (CAPM) IN STOCK MARKET
}

\begin{tabular}{|l|c}
\hline 1 & $\begin{array}{c}\text { Associate Professor, Department of } \\
\text { Management, Apex Institute of } \\
\text { Management \& Science, Jaipur, Rajasthan, } \\
\text { India. }\end{array}$
\end{tabular}

Purpose - The present study aims to examine the concept of Capital Asset Pricing Model (CAPM), the mechanism of Capital Asset Pricing Model (CAPM) and evaluate its applicability as tools that Investors and Traders can use to facilitate decision making related to stocks in Stock Market.

Design/methodology/approach - This paper uses secondary data to empirically examine the impact of Capital Asset Pricing Model in Stock Market. Since, Capital Asset Pricing Model occupies an important place in the Security Analysis and Portfolio Management, therefore this Model has been selected in order to bring to light the current mechanism prevailing in the Stock Market.

Findings- In this paper, it has been highlighted that CAPM can be strategically used to determine whether securities are overvalued or undervalued and whether the stocks are to be purchased or sold. Application of CAPM can be truly helpful in the process of decision making and can also help in buying or selling the securities at the right time and right price.

Research Implications- Application of CAPM in Stock Market carries a wide scope and this area needs to be worked on. A deeper understanding of CAPM will help investors and traders to determine optimum strategies, estimate and forecast precisely the value or the market price of the securities.

Practical Implications- This study also signifies an important implication of Capital Asset Pricing Model which is estimating the market price of the stock using equilibrium return and simultaneously aims to assess the applicability of this analysis in the Stock Market.

Originality- The study seeks to contribute towards the existing literature on usage of Capital Asset Pricing Model (CAPM) in Stock Market by giving a new perspective.

KEYWORDS: Capital Asset Pricing Model (CAPM), Capital Market Theory, Expected Return, Equilibrium Return, Sharpe Index Model, Stock Market

\section{INTRODUCTION}

Capital Asset Pricing Model (CAPM) was primarily developed by William F. Sharpe. CAPM is an important model in Security Analysis and Portfolio Management which provides the basis between return and systematic risk. CAPM is based on the underlying assumption that the risk premium component of a security's expected return is a function of that security's market risk. It basically provides a mechanism which explains the relationship between the expected return of a stock and its systematic risk. Financial analysts and experts can apply Capital Asset Pricing Model to estimate the degree of additional return above risk free return for a given level of systematic risk. CAPM has widely been considered as one of the most effective 
technique to estimate the cost of equity capital, and that's the reason why CAPM has become one of the most popular models for estimating the cost of equity capital. According to Shannon \& Robert (2000), CAPM is a Capital Market Theory model and it describes the market relationships that will result if investors behave in the manner prescribed by portfolio theory. One can easily remark that CAPM is a conceptual framework of modern Capital Market Theory. Capital Asset Pricing Model signifies market or systematic risk which cannot be diversified and market risk premium which is the excess market return over risk free rate. Capital Asset Pricing Model also embarks on the concept of Unsystematic risk which can be diversified by construction of portfolios and that's the reason why it is called as so known as diversifiable risk. Unsystematic risk is a function of uncertainty of returns based on the characteristics of the company or the industry to which the company is related. Unsystematic risk is not affected to a variation of returns in the market. Total risk of a security comprises of both systematic risk (market-based risk) and unsystematic risk (company or industry based).

Unsystematic risk can be enhanced by internal factors existing in the company like management factors, factors related to trade union, management policies or strategies or any volatility exising in the organization. CAPM also highlights the significance of the volatility index or the sensitivity index called Beta. Beta describes the sensitivity of returns of a stock with respect to the returns of the market. Thus, it is an important component of systematic risk. Risk Premium is the term which is used for the excess return earned above the risk free return and it is the reward accrued to the investors for taking the risk. CAPM also signifies a relationsip that with the increase in the value of Beta, the equilibrium return of the security also increases. Here, the inferences of Capital Market Theory become very vital for deriving the model which potrays the relationship between Expected Return of a stock and its Systematic Risk.

Thus, it has been rightly said that the Capital Asset Pricing Model describes the relationship between the expected return of a security, Risk Free Rate and Risk Premium. CAPM can be expressed in the form of equation as follows:

$$
R=R_{f}+\beta\left(R_{m}-R_{f}\right)
$$

Where, $\mathrm{R}=$ Expected Return from any security or Portfolio of Securities

$$
\begin{aligned}
& \mathrm{R}_{\mathrm{f}}=\text { Risk Free Rate of Return } \\
& \mathrm{R}_{\mathrm{m}}=\text { Expected rate of Return on }
\end{aligned}
$$

Market

$$
\beta=\text { Beta factor,i.e. Beta is }
$$

popularly called as Market sensitivity index or measure of systematic risk of individual security

CAPM model is used for the evaluation of the risk and return implications of Stocks and Portfolio of stocks. CAPM refers to the mechanism in which stocks are valued with their expected risk and returns. CAPM model reveals that the expected rate of return of a security consists of -

a) Risk Free rate of return $\left(R_{f}\right)$ b) Risk $\operatorname{Premium}\left(R_{m}-R_{f}\right) \quad$ c) Sensitivity Index

The Risk Premium expresses the difference between the Expected Market Return and Risk Free Rate. It shows that the Return of a stock varies directly with the Beta factor ( Systematic Risk) and therefore the value of expected rate of return of a stock is directly proportional to the Beta Factor $(\beta)$. The higher the value of Beta factor, greater is the expected rate of return, and the lower the value, the less will be the expected return. Thus, we can derive this inference that Expected Return of a Security in case of CAPM, is dependent on the Market Sensitivity Index and this important factor affecting the Expected Return of the Security i.e. Market Sensitivity (BETA). The risk associated with securities can be categorized into:

a) Unsystematic Risk -_Unsystematic Risk is that component of Risk which arises on account of firm's specific factors and can be eliminated or diversified by investing in a large portfolio of securities.

b) Systematic Risk -Systematic Risk is that component of Risk which is associated with market conditions like Boom, Recession, etc. and is dependent on the market. Systematic Risk cannot be eliminated or diversified by investing in a large portfolio of securities, thus it is unavoidable even by diversification of the portfolio. The systematic risk of a stock is measured with the help of Beta which is based on the sensitivity to market returns A Beta of 2 implies that if the market return increases or decreases by $10 \%$, the security's return is expected to increase or decrease by $20 \%$ respectively. On the other hand, if the value of Beta is 0.50 , then it describes that the security return increases or decreases by half of the movement shown in the returns of the market. A Beta of 0 denotes a risk-free security like a Treasury Bills or government securities. Thus, Beta is a measure of the volatility of a stock in relation to movement in the returns of the market. If Beta of a particular share is high, it means its prices increases more, if the market increases. Similarly its price will decrease more, if the market crashes down.

Therefore, Beta is the index of Systematic Risk, and the higher the riskiness of a security, the higher the value of Beta. A security with a Beta value greater than 1 is referred to an Aggressive Security. A Security with a Beta less than 1 is referred to as Defensive Security; and the security with Beta equals or nearing 1 is referred to as Normal Security. Beta is calculated on the following assumptions: 
a) Investors are rational

b) Investors seek a higher return for a risky security

c) Investors can differentiate between a Risky and Risk Free Security.

Thus, it is clear that the information related to the following aspects are needed to apply CAPM:

1) Risk Free Rate $\left(R_{f}\right)$ - The rate of return on assets like Treasury Bills (T-Bills), Money market funds or Bank deposits are categorized as Risk Free Rate. The maturity period of TBills and Bank Deposits is taken to be less than 1 year. Such assets have negligible default risk.

2) Risk Premium $\left(R_{m}-R_{f}\right)$ - Market Risk Premium or Risk Premium on market Portfolio is the difference between the expected return on the market portfolio and risk free rate of return.

3) Beta ( $\beta$ )- Beta measures the risk volatility of an individual asset relative to the market portfolio. Assets with Beta less than 1 are called Defensive Assets whereas Securities with greater than lare called Aggressive Securities. Risk Free Assets have a Beta equal to 0 .

CAPM is very significant in deciding whether the decision maker should buy, hold or sell the securities by comparing the required rate of return with the expected return. If the Expected Return is greater than the CAPM Return then the trader can buy the security. If the Expected Return is less than the CAPM Return then the trader should sell the security. If the Expected Return is equal to the CAPM Return then the trader can hold the security for some more time till some trends of the particular security comes up in the stock market. CAPM can also be used to estimate the expected market price of the stock. This can be estimated with the help of the following statistic:

Expected Market Price of the Stock $=D_{l} /(R-g)$

Where $D_{1}$ is the Expected Dividend of the security and it can be calculated as follows:

$\mathrm{D}_{1}=\mathrm{D}(1+\mathrm{g})$

While $\mathrm{D}$ is the current dividend of the stock and $\mathrm{g}$ is the growth rate

$\mathrm{R}$ is the CAPM Return or the equilibrium return

\section{Assumptions of CAPM}

One of the most important assumption used in CAPM is that the conditions of Stock Market are Perfect. This signifies that all securities can be bought or sold smoothly and they are devoid of any kind of transaction costs or taxes. Then Capital Asset Pricing Model is based on the assumption that there is a risk-free rate of return which remains constant for all the situations prevailing in the stock market. While applying CAPM, the estimates are made for single period. Another important assumption is pertaining to the nature of the investors that the investors are considered rational. This implies that for a low level of risk they expect a lower return from the security and for a higher level of risk, they expect higher return from that security. The investors also consider diversification strategies to reduce the level of risk. Investors considers return as the greatest reward for taking a significant amount of risk and the return of a stock is perceived to be comprising of Capital gains and Dividends, etc. The assumptions are very significant because they provide a benchmark for the investors for which assumptions they need to change. Obviously, the extent to which these assumptions are consistent will have a bearing on the validity of the CAPM for the valuation of any company and portfolios. The company-specific risk premium may be rewarded in expected returns for various stocks. The CAPM is considered a "singleperiod" model in the equilibrium and is defined in terms of a constant risk-free rate and market risk premium.

\section{IMPLICATION OF CAPM IN SINGLE INDEX MODEL}

William F. Sharpe suggested that the Return on a Security could be regarded as linearly related to a Single Index of the Market like Sensex or Nifty which consists of all the securities traded on the Market. This formed the basic framework for Single Index Model or Sharpe Index Model. The calculation of Return in CAPM also made use of Market return besides other factors like Risk Free Rate, Risk Premium, etc. CAPM and Single Index Model carries the same perspective that when Market moves up i.e. when the Market Index (Sensex or Nifty) rises , prices of most of the shares rises and vice-versa. It may be noted that the prices of all shares may not move at the same proportion. So we can derive this fact that Stock Prices are related to the Market Index and this inference could be used to estimate the return on stock in both CAPM and Single Index Model. In other words, the relationship between the Returns of Securities can be obtained by relating the Return on a stock to the Return on a Stock Market Index like Nifty or Sensex. Hence, the Single Index Model developed by Sharpe is based on the assumption that all the covariances of Security Returns can be explained by a single factor which is called as the Market Index line Sensex or Nifty. By this reason, this model is popularly called as Single Index Model. The Sharpe Index Model is based on the concept of Returns arising due to a Single Factor (Market Index like Nifty or Sensex), which is quite simple as compared to Markowitz's method of calculating all covariances of all assets in the portfolio. A version of this model is called Market Model which uses a Market Index such as SENSEX as the factor. In the Sharpe Index Model, the Return of a security is attributed to the given aspects:

a) Return which can directly be related to the Market factors

b) Return which is independent of the Market 
Single Index Model has substantially reduced the number of required inputs when estimating the Portfolio Risk as compared to Markowitz model. Instead of estimating the Correlation or Covariance between every pair securities as required by the Markowitz Model, the Sharpe Index Model requires that each security's Return should be calculated by using Market Index like Nifty or Sensex and we can apply the following relationship:

$$
\mathrm{R}=\alpha_{\mathrm{x}}+\mathrm{R}_{\mathrm{m}} \beta_{\mathrm{x}}
$$

$\mathrm{R}=$ Expected Return of the Security

$\alpha_{\mathrm{x}}=$ Alpha Coefficient (Non Market component of the return of Security)

$\mathrm{R}_{\mathrm{m}}=$ Rate of Return from the Market Index

$\mathrm{B}_{\mathrm{x}}=$ Beta Factor of the Security

The variable $\alpha$ in the above equation is the non-market component and it is that component which is independent of the market. Even when the return from the market index is zero, then also might yield some return as it is independent of the market return. The Beta factor indicates the Sensitiveness of the Stock return to the changes in the Market Return. Sharpe's optimal portfolio would consist of only those securities which have excess return to Beta ratio above a cut-off point. The selection of a security is directly depending on its excess return Beta ratio. The Security's Excess Return over Beta ratio is an important concept in the analysis of the security and so is Covariance. Covariance is a tool which measures the extent to which the return of a particular stock and the market's return move together in the same direction or in the opposite direction. Covariance is a measure of the two variables' tendency to vary in the same direction and in the same relative amounts. Thus, in order to apply the Capital Asset Pricing Model(CAPM) as well as Single Index Model (Sharpe Index Model) to estimate the Equilibrium Return of a Stock, it is necessary to estimate beta. This is often accomplished by calculating the value of Beta according to the mechanism given below:

$\operatorname{Beta}(\mathrm{x}) \boldsymbol{\beta}_{\mathrm{x}},=$ covariance $(\mathrm{x}, \mathrm{m}) / \operatorname{variance}(\mathrm{m})$ where: $\operatorname{Beta}(x)=$ Expected beta of the stock of company $\mathrm{x}$

$\mathrm{Rx}=$ Return on stock $\mathrm{x} ; \mathrm{R}^{\prime} \mathrm{x}=$ Average Return of stock $\mathrm{X}$

$\mathrm{Rm}=$ Return on market portfolio; R'm= Average Return on Market Portfolio

Covariance $(\mathrm{x}, \mathrm{m})=$ Expected covariance between the excess return (Rx-Rf) on stock of company $x$ and the excess market return (Rm-Rf)

Covariance $(\mathrm{x}, \mathrm{m})=\sum\left[\left(\mathrm{Rx}-\mathrm{R}^{\prime} \mathrm{x}\right)(\mathrm{Rm}-\mathrm{R}\right.$ 'm $\left.)\right] / \mathrm{N}$

Variance $(\mathrm{m})=$ Expected variance of excess return on the overall stock market

$\operatorname{Variance}(\mathrm{m})=\sum\left(\mathrm{Rm}-\mathrm{R}^{\prime} \mathrm{m}\right)^{2} / \mathrm{N}$

Lets take a case to understand the whole mechanism of calculating the value of Beta. The return (in percent) for $\mathrm{ABC}$ stock and the Return from Market for a 12 month period are presented:

\begin{tabular}{|c|c|c|}
\hline Month & ABC Return(Rx) & Market Return (Rm) \\
\hline 1 & -0.75 & -0.35 \\
\hline 2 & 5.45 & -0.49 \\
\hline 3 & -3.05 & -1.03 \\
\hline 4 & 3.41 & 1.64 \\
\hline 5 & 9.13 & 6.67 \\
\hline 6 & 2.36 & 1.13 \\
\hline 7 & -0.42 & 0.72 \\
\hline 8 & 5.51 & 0.84 \\
\hline 9 & 6.80 & 4.05 \\
\hline 10 & 2.60 & 1.21 \\
\hline 11 & -3.81 & 0.29 \\
\hline 12 & -1.91 & -1.96 \\
\hline
\end{tabular}


The yield on Treasury Bills during the course of research work was $4.38 \%$.

The working of the Beta of the given stock is given below:

\begin{tabular}{|c|c|c|c|c|c|c|}
\hline Month & $\mathbf{R x}$ & $\mathbf{R m}$ & Rx-R'X & Rm-R'm & $\left(R x-R^{\prime} x\right)\left(R m-R^{\prime} m\right)$ & (Rm-R'm) \\
\hline 1 & -0.75 & -0.35 & -2.86 & -1.41 & 4.0326 & 1.9881 \\
\hline 2 & 5.45 & -0.49 & 3.34 & -1.55 & -5.177 & 2.4025 \\
\hline 3 & -3.05 & -1.03 & -5.16 & -2.09 & 10.7844 & 4.3681 \\
\hline 4 & 3.41 & 1.64 & 1.3 & 0.58 & 0.754 & 0.3364 \\
\hline 5 & 9.13 & 6.67 & 7.02 & 5.61 & 39.3822 & 31.4721 \\
\hline 6 & 2.36 & 1.13 & 0.25 & 0.07 & 0.0175 & 0.0049 \\
\hline 7 & -0.42 & 0.72 & -2.53 & -0.34 & 0.8602 & 0.1156 \\
\hline 8 & 5.51 & 0.84 & 3.40 & -0.22 & -0.748 & 0.0484 \\
\hline 9 & 6.80 & 4.05 & 4.69 & 2.99 & 14.0231 & 8.940 \\
\hline 10 & 2.60 & 1.21 & 0.49 & 0.15 & 0.0735 & 0.0225 \\
\hline 11 & -3.81 & 0.29 & -5.92 & -0.77 & 4.5584 & 0.5929 \\
\hline \multirow[t]{2}{*}{12} & -1.91 & -1.96 & -4.02 & -3.02 & 12.1404 & 9.1204 \\
\hline & $\begin{array}{l}\mathrm{R}^{\prime} \mathrm{x}= \\
2.11\end{array}$ & $\begin{array}{c}\mathrm{R}^{\prime} \mathrm{m}= \\
1.06\end{array}$ & & & $\begin{array}{c}\sum\left(\mathrm{Rx}-\mathrm{R}^{\prime} \mathrm{x}\right)\left(\mathrm{Rm}-\mathrm{R}^{\prime} \mathrm{m}\right) \\
=80.7013\end{array}$ & $\begin{array}{l}\sum\left(\mathrm{Rm}-\mathrm{R}^{\prime} \mathrm{m}\right) \\
=59.392\end{array}$ \\
\hline
\end{tabular}

$$
\begin{aligned}
\text { Covariance }(\mathrm{x}, \mathrm{m})= & \sum\left[\left(\mathrm{Rx}-\mathrm{R}{ }^{\prime} \mathrm{x}\right)\left(\mathrm{Rm}-\mathrm{R}^{\prime} \mathrm{m}\right)\right] / \mathrm{N} \\
& =80.7013 / 12 \\
& =6.725
\end{aligned}
$$

Variance $(\mathrm{m})=\sum(\mathrm{Rm}-\mathrm{R} ' \mathrm{~m})^{2} / \mathrm{N}$

$$
=59.392 / 12
$$

$$
=4.949
$$

$$
\begin{aligned}
\operatorname{Beta}(\mathrm{x}) \boldsymbol{\beta}_{\mathrm{x}} & =\text { covariance }(\mathrm{x}, \mathrm{m}) / \operatorname{variance}(\mathrm{m}) \\
& =6.725 / 4.949 \\
& =1.36
\end{aligned}
$$

Since Beta of the concerned stock is 1.36 which is greater than 1 , therefore this stock is termed as an Aggressive Stock.

Using Capital Asset Pricing Model (CAPM), we can calculate the equilibrium return in the following manner:

$$
\mathbf{R}=\mathbf{R}_{\mathrm{f}}+\boldsymbol{\beta}\left(\mathbf{R}_{\mathrm{m}}-\mathbf{R}_{\mathrm{f}}\right)
$$

Where, $\mathrm{R}=$ Expected Return from any security

$\mathrm{R}_{\mathrm{f}}=$ Risk Free Rate of Return; Here $\mathrm{Rf}=4.38 \%$ (yield on Treasury Bills)

$\mathrm{R}_{\mathrm{m}}=$ Expected rate of Return on Market; here $\mathrm{Rm}=1.06$ ( for 12 month period)

$\beta=$ Beta factor, here $\boldsymbol{\beta}=\mathbf{1 . 3 6}$

$$
\begin{aligned}
\mathrm{R} & =4.38+1.36(1.06-4.38) \\
& =4.38-4.5152 \\
& =-0.1352 \%
\end{aligned}
$$

It can be deduced from the above calculations that the investors should buy the above stock as the Average Return of $2.11 \%$ is greater than the CAPM Return of $-0.1352 \%$. The return are in line with the equilibrium return, so one can invest in the above stock

Now using Sharpe Index Model, the alpha factor can also be calculated in the following manner:

$$
\mathbf{R}=\boldsymbol{\alpha}_{\mathrm{x}}+\mathbf{R}_{\mathrm{m}} \boldsymbol{\beta}_{\mathrm{x}}
$$

$\mathrm{R}=$ Expected Return of the Security

$\alpha_{x}=$ Alpha Coefficient (Non Market component of the return of Security)

$\mathrm{R}_{\mathrm{m}}=$ Rate of Return from the Market Index; here $\mathrm{Rm}=1.06$

$\beta_{x}=$ Beta Factor of the Security; here Beta, $\boldsymbol{\beta}_{\mathrm{x}}$ is 1.36

Now considering the Average Return of the Security which is 2.11 , the value of alpha will be as

$R=\alpha_{x}+R_{m} \beta_{x}$

$2.11=\alpha_{x}+1.06(1.36)$

$2.11=\alpha_{x}+1.4416$

$\alpha_{x}=0.6684$

So the value of alpha which represents the nonmarket component of the return of the stock is 0.6684 if we are taking the average return of the stock.

Now considering the Equilibrium Return of the Security according to CAPM which is

-0.1352 , the value of alpha will be as :

$R=\alpha_{x}+R_{m} \beta_{x}$

$-0.1352=\alpha_{X}+1.06(1.36)$

$-0.1352=\alpha_{x}+1.4416$

$\alpha_{x}=1.3064$

So, the value of alpha which represents the nonmarket component of the return of the stock is 1.3064 if we are taking the Equilibrium Return of the Security according to CAPM.

\section{FINDINGS}

1. Beta of the concerned stock is 1.36 which is greater than 1, therefore this stock is termed as an Aggressive Stock.

2. It is suggested that the the Average Return of $2.11 \%$ is greater than the CAPM Return 
of $-0.1352 \%$. The average return is greater than the equilibrium return, so it is advisable to invest in the stock in consideration.

3. Now considering the Average Return of the Security which is 2.11 , the value of alpha factor which represents the non-market component of the return of the stock is 0.6684 .

4. Considering the Equilibrium Return of the Security according to CAPM which is 0.1352 , the value of alpha factor which represents the non-market component of the return of the stock is 1.3064 . The higher value of alpha considering the equilibrium return signifies the strong fundamentals of the company's stock.

\section{CONCLUSION}

The Capital Asset Pricing Model (CAPM) is a great financial technique for the analysis of a security in the stock market. CAPM explains an important mechanism between Risk Free Rate, Beta coefficient and Market Risk Premium. The CAPM has several applications, which may be very much relevant for the market as a whole or for any particular company or investment. The CAPM helps in calculating the equilibrium return which can be very vital in estimating the market price of the stock. Thus, we can conclude that CAPM can be effectively used to anticipate the value of the security. CAPM can be strategically used to determine whether securities are overvalued or undervalued and whether the stocks are to be purchased or sold. Capital Asset Pricing Model is one of the most fundamental models in modern finance theory and offers a great scope of study for the relationship between risk and expected return. The CAPM facilitates in calculating the required rate of return, which represents a marketbased opportunity cost. CAPM is a single-factor model, comprising the beta coefficient, which measures the degree of non-diversifiable risk. It reflects the change in a security's return in response to a change in the market return. The CAPM has a great scope and potential for building an optimum portfolio in the stock market.

\section{REFERENCES}

1. Bodie, Z., Kane, A., and Marcus, A., (2009), Investments, 8th edition, McGraw-Hill, New York.

2. Goodwin, T., (1998), The information ratio, Financial Analyst Journal, 54, pp. 34-43.

3. Green, R. C., (1986), Positively weighted portfolios on the minimum-variance frontier, Journal of Finance, 41, pp. 1052-68.

4. Korkie, B., and H. J. Turtle, (2002), A meanvariance analysis of self-financing portfolios, Management Science, 48, pp. 427-43.

5. Markowitz, H., (1959), Portfolio Selection: Efficient Diversification of Investments, John Wiley, New York.
6. Richardson, H., (1989), A minimum variance result in continuous trading portfolio optimization, Management Science, 35, pp.104352.

7. Roll, R., (1992), A mean-variance analysis of the tracking error, Journal of Portfolio Management, 18, pp.16-21.

8. Ross, S. A., (1976), The arbitrage theory of capital asset pricing, Journal of Economic Theory, 13, pp.341-360.

9. Ross, S., (1977), The capital asset pricing model $(C A P M)$, short sales restrictions and related issues, Journal of Finance, 32, pp.179-81.

10. Shannon, P. and Robert, F., (2000), Valuing A Business: The Analysis and Appraisal of closely held companies, Fourth Edition, McGraw-Hill, New York.

11. Sharpe, W. F., (1970), Portfolio Theory and Capital Markets, McGraw-Hill, New York. 